stone of Broken Hill ; it seems to bear some close relation to granilite. The specimen is composed of quartz, garnet, and felspar fragments. This rock holds out hopes that minerals of economic value may occur in these regions.

The peninsula on which we landed at Cape Adare must be some seventy acres in extent; on the top of the guano were lying the primitive nests of the penguins, composed of pebbles. Some hundreds of yards up these landslips I came upon two dear seals, which from their appearance must have lain there several years. I made a thorough investigation of the landing-place, thecause I believe it to be a place where a future scientific expedition might safely stop even during the winter months. Several accessible spurs lead up from the place where we were to the top of the cape, and from there a gentle slope leads on to the great plateau of South Victoria Continent. The presence of the penguin colony, their undisturbed old nests, the appearance of the dead seals, the vegetation on the rocks, and, lastly, the fat table of the cape above, all indicated that here the unbound forces of the Antarctic circle do not display the whole severity of their powers. Neither ice nor volcanoes seemed to have raged at the peninsula at Cape Adare, and I strongly recommend a future scientific expedition to choose this spot as a centre for operations. At this place there is a safe situation for houses, tents, and provisions. I myself am willing to be the leader of a party, to be landed either on the pack or on the mainland near Colman Island, with Ski, Canadian shoes, sledges, and dogs. From there it is my scheme to work towards the south magnetic pole, calculated by Ross to be in $75^{\circ} 5^{\prime}$ and $150^{\circ}$ E., Colman Island lying in $73^{\circ} 36^{\prime} \mathrm{S}$. and I70 $2^{\prime} \mathrm{E}$. I should have to travel about 160 miles to reach the south magnetic pole. Should the party succeed in penetrating so far into the continent, the course should be laid, if possible, for Cape Adare, in order to join the main body of the expedition there.

As to the zoological results of future researches, I expect great discoveries. I base my expectations on one point-on the scars found on the seals, which in my opinion point to the existence of a large unknown mammal within the Antarctic circle. Although the white polar bear of the Arctic has never been found in the south, I should not be surprised to discover similar species there. It would indeed be remarkable if, on the unexplored Victoria Continent-which probably extends over an area of 8,000,000 square miles, or about twice the size of Europe-animal life hitherto unknown on the southern hemisphere should not be found.

It is of course possible that the unknown land around the axis of rotation may consist of islands, only joined by perpetual ice and snow ; but the appearance of the land, and the colour of the water with its soundings, in addition to the movements of the Antarctic ice, point to the existence of a mass of land much more extensive than a mere island.

It is true that the scientific results of this expedition have been few, but my little work gives me at least the satisfaction of feeling that it will fill a useful, if molecular, place among those strong arguments which for years have accumulated, and which prove that further delay of a scientific expedition to South Victoria Continent can scarcely be justified.

\section{WEATHER FALLACIES.}

I $\mathrm{N}$ the long and patient pursuit which the attainment of all accurate knowledge exacts from man, it may sometimes be instructive to turn one's gaze backward and contemplate the errors which have been corrected, the fallacies which have been demolished, and the superstitions which have been lived down and this consideration has prompted me to take for the subject of this year's address that wide range of human opinions which may fitly be classed under the head of "Weather Fallacies."

Nothing could have been more in accordance with the law of growth in other branches of knowledge than that Meteorology should, in its earliest dawn, have been with difficulty able to emerge from the mists and darkness of guesses and surmises such as have surrounded the transfer of any truth from the barbaric to the philosophic stage.

It is to the Greeks that we must look for the first real weather observations after the matter had passed through what may be called the mere savage phase; and we find Hesiod, Theophrastus, and Aratus presenting us with an early code of rules, which serve at least to show us how little we have ourselves advanced in some matters since their time.

An address delivered to the Royal Meteorological Society, by Mr. Richard Inwards, President. (Reprinted from the Ouarterly Jou nal of the Society.) NO. I 346 , VOL. 52 ]
One of our Fellows, Mr. J. G. Wood, has just given to the world an excellent and scholarly translation of the work of Theophrastus, which has not previously been put in an English garb, and Mr. Wood has done the whole country a great service in giving us this translation of the "Winds and Weather Signs," a book which contains a host of rules and observations about the weather, and which, as might have been expected from the production of the favourite pupil of Plato and Aristotle, is singularly free from errors of the grosser and more superstitious kind, such as were plentifully produced in Western Europe many centuries later.

But long before the time of 'Theophrastus, and probably very soon after the invention of agriculture itself, there were weather gods and weather fallacies; for we find that Jupiter Tonans and Pluvius-the thunderer and the rain-maker-were set by men on the highest pedestals. And centuries after this, Lucian tell us that it was usual in his time to offer prayers for suitable weather, and he recounts in his " Dialogues" how two countrymen were at the same time offering up contrary petitions-one that not a drop of rain might fall until he had completed his harvest, while the other prayed for immediate rain, in order' to bring on his backward crop of cabbages-both suppliants only too sure to find that the ears of the image were deaf as the stone of which they were made, and that the wheels of the universe would not wander or turn back for any selfish ends of man.

In considering these early times, when the weather had to be studied from cloud, sky and sea, and from the behaviour of the animals and plants, we must be ready to excuse men for doing that which is still too frequently a cause of error, viz. foretelling what they most wished for, and putting down as universal law that which was only a coincidence of totally independent events. In considering weather fallacies it will be impossible to follow a chronological order, so I shall treat them, or rather a small portion of them, under the heads of saints' day fallacies, sun and moon fallacies, and those concerning animals and plants, while finally I shall consider the almanack makers, weather prophets and impostors who have from time to time furnished the world with materials for its credulity or its ridicule.

The first class of weather fallacies which I shall scarcely more than mention, are those which refer to the supposed connection between the weather of any day in the week or year, and that of any other period, and it may be as well to state at the outset that there is no kind of foundation in fact for any of these socalled rules. They are for the most part born of the wish to see certain kinds of weather at certain times of year, and, like all these predictions, were faithfully remembered when they came true, and promptly forgotten when they failed. One has often heard-

"Fine on Friday, fine on Sunday."

Or that "Friday is the best and worst day of the week," and the superstition even extends to hours of the day, for we have-

"Rain at seven, fine at eleven,"

which is only another way of saying that rain does not usually last four hours, and the rule generally fails when applied to daily experience ; but the host of proverbs connected with saints' days are more difficult to deal with, on account of the longer time which elapses between the prophecy and its fulfilment or failure. All or most of these proverbs concern the days of certain saints, though I think no one imagines that this is anything more than a convenient method of fixing the date, because our ancestors had a saint for every day, so that they naturally referred to the day by his name.

There are forty weather saints, among the most prominent of whom is undoubtedly St. Swithin, whose day is July 15, and the superstition is that if it should rain on that day it will rain for forty days after. Now, as Mr. Scott observes, this date is very near a well-known bad time in wet years, as the terms, long in use, of "St. Margaret's flood" and "Lammas flood "abundantly testify. The fact that some of these heavy rains began on July I 5 has been enough material for the adage-monger, and so we have another " universal" law laid down, a law which is, however, constantly broken, as every student of the weather very well knows. The whole thing is a fallacy of the most vulgar kind, and ought speedily to be forgotten, together with all the adages which make the weather of any period depend on that of a distant day.

Turning in weariness from this class of superstitions, which may be said to belong to the self-exploding order, we are next met by an extensive array of authorities who, under the protecting 
shield of astronomy, profess to have framed infallible rules for the weather as judged from the ever-varying relative positions of the sun, moon, and planets. They attack us systematically and persistently, appealing to analogy, to reason, and to common sense. But it is sometimes necessary to be on our guard, even against common sense, in considering problems to which uncommon sense has for centuries been devoted without avail. The well-known action of the sun and moon upon the ocean tides is generally the starting point of these theorists, and it is soon shown to common sense that when the earth is nearer the sun, or the moon is nearer to the earth (it being remembered that they move in elliptic orbits), or when both sun and moon are, as it were, pulling together, as at new moon, there ought to be a tide of atmosphere caused by their influence similar to the tides of the ocean, which such agencies undoubtedly produce. But we find that whatever so-called reason, analogy, and common sense may seem to dictate, the facts will not follow in the path marked out for them; and the atmospheric tides refuse to ebb and flow, except in a most infinitesimal degree, quite disproportioned to their supposed moving forces. The theorists must try again, and they do so by pointing out that the moon and earth move in planes which are inclined to each other at an angle, and that at some times of the year the attraction of the sun and moon are acting in somewhat widely diverging lines, whilst at others they are pulling more nearly in the same plane. Here is, they say, a clear case. At times, when the angle is greatest, there should at any rate be worse weather caused by the conflicting forces. When the moon is said to be "on her back," or, in other words, when the line of the shadow boundary of the half-moon or crescent is much inclined to the earth's axis, then is the time, say they, for tempests and commotions to come. But again the spirits from the "vasty deep" do not come when called, and we have to invent other causes for our earthly disturbances.

It may be safely said that a new moon theory as to the weather comes out at least once a year, and it has been attempted to connect the honoured name of Sir William Herschel with a table which professed to show the dependence of weather changes on those of the moon.

By the kindness of Mr. Symons I am able to show you on the screen a much magnified representation of this production, now very scarce, and which has the name of Herschel in large capitals, no doubt as a sort of ballast to give it weight and steadiness, though it does not definitely state that Herschel had anything to do with it. Herschel's own letter on the subject runs as follows :-

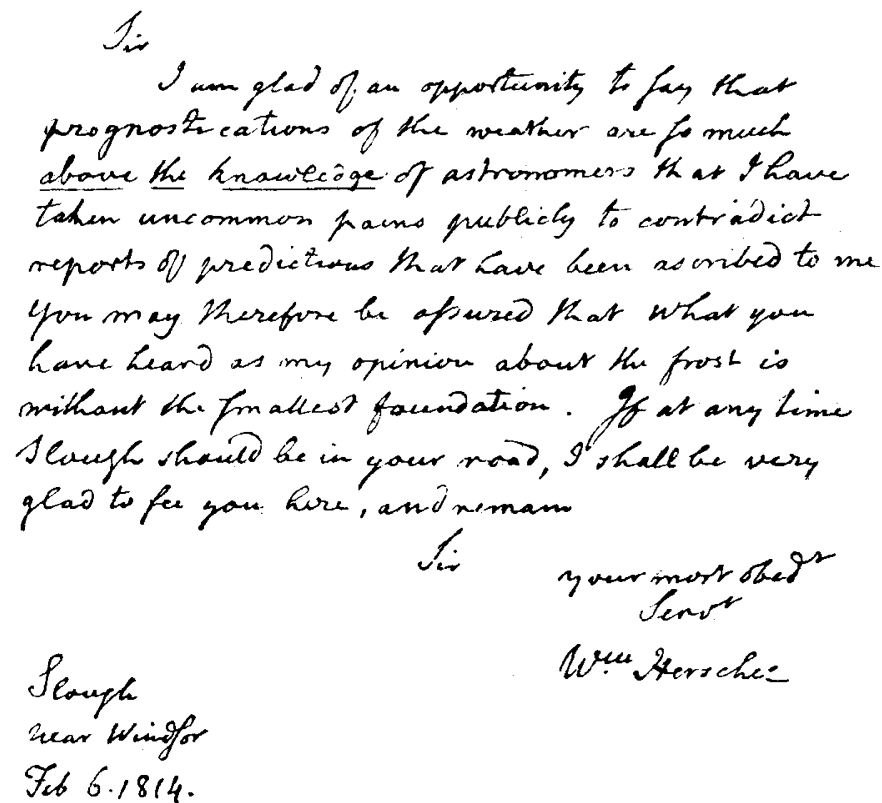

0.1814

So that any Fellow of this Society who sees one of these diagrams in the future will know that it is a fraud.

Of course it is in the power of every one to check the predictions which are so often issued with respect to the changes of the weather taking place at the change of the moon; but NO. I 346 , VOL. 52$]$ many eminent men have occupied themselves with the subject, and the result is that no correspondence between the two classes of phenomena has been established.

Dr. Horsley examined the weather tables of $\mathbf{1 7 7 4}$, as published by the Royal Society, and out of 46 changes of weather in that year only ten accurred on the days of lunar influence, only two of them being at the new moon, and none at all at the full. M. Flarguergues, of Viviers, found 'alsoias athe result of twenty years' observations, that the barometer readings taken when the moon was furthest from the earth averaged 755 millimetres, and when nearest, 754 millimetres, showing a difference of I millimetre or about $\mathrm{O} 4 \mathrm{inch}$, and this in a direction against the theory, the pressure being greater by that amount when the moon was farthest from the earth.

Various other weather seers have pinned their faith on lunar cycles, and have predicted that weather changes would repeat themselves, as soon as the sun and moon got back into the same relative positions, which they do in nineteen years, with only an error of an hour and a half. Others, such as Mr. G. Mackenzie, advocated a cycle of 54 years, but it may be summarily stated that all the cycles have broken down, and that, as far as we know, there is no definite period after which the weather changes repeat themselves.

Other fallacies about the moon are numerous, such as that the full moon clears away the clouds; that you should only sow beans or cut down trees in the wane of the moon; that it is a bad sign if she changes on a Saturday or Sunday; that two full moons in a month will cause a flood; that to see the old moon in the arms of the new brings on rain, and many others, of which a catalogue alone would take up a good deal of space. M. Flammarion says that " the moon's influence on the weather is negfígible. The heat reaching us from the moon would only affect our temperature by 12 millionths of a degree; and the atmospheric tides caused by the moon would only affect the baromètric pressure a few hundredths of an inch-a quantity far less than the changes which are always taking place from other causes." On the whole we are disposed to agree with the rhyme which thus sums up the subject :

$$
\begin{aligned}
& \text { The moon and the weather } \\
& \text { May change together; } \\
& \text { But change of the moon } \\
& \text { Does not change the weather. }
\end{aligned}
$$

Even the halo round the moon has been discredited, for $\mathrm{Mr}$. Lowe found that it was as often followed by fine weather as by rain, and Messrs. Marriott and Abercromby found that the lunar halo immediately preceded rain in 34 cases out of $6 \mathrm{I}$. We always have a lingering hope that some future meteorologist will disentangle the overlapping influences, and arrive some day at a definite proof that our satellite after all has something to do with our weather.

About the sun, also, there are many fallacies, and ever since the discovery that the spots which appear on his surface have a period of greatest and less frequency, there have been theorists in shoals who have sought to prove that this fact rules our weather. It has undoubtedly been found that the frequency of sun-spots and the variations of the magnetic needle are intimately connected; arid it is almost equally well established that the aurora appears and disappears in some sort of sympathy with the sun-spot variations. But this, up to the present, is as far as we can get in this direction, for our weather seems to have no definite relation to these changes.

The more recent discoveries of prominences visible round the disc of the sun during an eclipse, and of the light clouds only seen in M. Deslandres' spectro-photographs, will no doubt call out new weather theories Gn the subject. And I must confess to a wish that those mysterious flame-like bodies rushing from the sun millions of miles into space, will be found to have some influence on the upper layers of our earth's atmosphere; but I also hope that we may be saved from a theory on the subject until more facts are before us.

Coming down to earth again, we are met by a long array of fallacies connected with the behaviour of animals and plants, and which have a supposed connection with weather changes. Few of these are so well grounded that they may be considered as proved, and as nothing is sacred to a meteorologist, our veteran 
Fellow, Mr. E. J. Lowe, F.R.S., has endeavoured to put some of the rules from this source to the test of definite observation. He took a number of well-known signs said to indicate change, and carefully noted what happened after each sign, and although he does not say that all indications from animals, birds and plants are useless, yet certainiy those he did investigate seemed utterly to break down.

He took the well-known signs of bats flying about in the evening, many toads appearing at sunset, many snails about, fish rising much in lake, bees busy, many locusts, cattle restless, landrails clamorous, flies and gnats troublesome, many insects, crows congregating and clamorous, spider-webs thickly woven on the grass, spiders hanging on their webs in the evening, and ducks and geese making more than usual noise. Mr. Lowe found that in 361 observations of the above signs, they were followed 213 times by fine, and only 148 times by wet weather; so that even after the prognostications for rain, there was a greater preponderance of fine weather. He called a day fine when no rain was measurable in the rain gauge. Mr. Lowe says that even swallows flying low cannot be depended on, as, especially at the close of summer and autumn, they almost invariably skim the surface of the ground, and Mr. Charles Waterton, the naturalist, decided, after careful observation, that the unusual clamour of rooks forms no trustworthy sign of rain. These must, therefore, swell the list of fallacies, although there are many other rules which have not been so carefully examined, but which may still be true. My own impression is that although it is painful to dismiss the animals from their ancient position as weather prophets, we may consider them as indicating what they feel, rather than as predicting what is to come, and that their actions before rain simply rise from the dampness, darkness or chilliness preceding wet weather, and which render these creatures uneasy, but not more so than they affect man himself. The sheep turning its back to the wind (one of the best known signs of rain) is probathly only that it may shelter its least protected part from the effects of the weather; and many of you must have observed sheep sheltering their heads from the heat by getting them into the shade of each other's bodies in a similar way.

As to cows scratching their ears, and goats uttering cries, and many other signs of bad weather, they are at least very doubtful whilst the adage about the pig which credits him with seeing the wind, carries with it its own condemnation.

The medicinal leech is still left on the list of weather prophets, though he has no doubt had his powers exaggerated; and two books have been written about his behaviour during changes of weather. One is by Mrs. Wonllams, who, during a long illness watched a leech in a bottle, and carefully noted what it did; and the other is by a gentleman at Whitby, who came to the conclusion that the leeches could be made to give audible and useful storm warnings. So he contrived the instrument, of which I now show you a drawing taken from his book. No one would imagine from its appearance what its use could be. It consisted of twelve glass bottles each containing a leech in water, and so arranged in a circle, in order, as the humane inventor states, that the leeches may see each other and not endure the affliction of quite solitary confinement-this rather reminds us of Isaac Walton, who told his pupil to put the hook into the worm "tenderly, as if he loved it"--in each bottle was a metal tube of a particular form, and which was made somewhat difficult for a leech to enter, but into which it would endeavour somehow to creep before a thunderstorm, according to its nature. In each tube was a small piece of whalebone, to which a gilt chain was attached, and so arranged, on the mouse-trap principle, that when the whalebone was moved the bell at the top of the apparatus was rung by means of the chain. There were twelve leeches, so that every chance was given that one at least would sound a storm signal. The author called this apparatus the "Tempest Prognosticator," a name which he preferred-and I think we shall agree with him-to that of atmospheric electric telegraph conducted by animal instinct. He went on to state in his little book that he could, if required, make a small leech ring the great bell of St. Paul in London as a signal of an approaching storm. The book is written in all seriousness, and a number of letters are appended from gentlemen who certify that correct atmospheric indications were at various times given by the leeches. The name of the inventor of this ingenious contrivance was Dr. Merryweather-himself a learned leech.

Plants have also their advocates as weather indicators; and there is no doubt that in most cases they act in sympathy with changes in the dampness, gloominess, or chilliness of the air, and as these conditions generally precede rain, one cannot term the indications altogether fallacious. The pimpernel and the marigold close their petals before rain, because the air is getting damper, while the poplar and maple show the under surface of their leaves for a similar reason. Indeed, an artificial leaf of paper may may be máde to do the same thing, if constructed on the same principle as the natural one - a hard thin paper to represent the upper side of the leaf, and a thicker unsized paper for the lower side; these will, if stuck together, curl up or bend down in sympathy with the hygroscopic condition of the air. A slip of ordinary photographic paper will do the same, and will curl up at once when placed on the hand.

The same slackness which moisture produces in plants applies in some degree also to insects, some of which can only fly in sunshine, so that there is a chain of weather signs all following from a little dampness in the air. The flowers close their petals and shut in their honey, the insects cannot fly so high, and the swallows seeking them skim the surface of the earth, and even then the threatened shower may not come.

In I892 attention was directed to a plant, the Abrus precatorius, a beautiful shrub of the mimosa kind, which has the property of being sensitive in a high degree, so that its pinnate leaflets go through many curious movements, and it was claimed that these form a guide of unerring certainty to foreshow the coming weather. Even earthquakes were said to be predicted by this wonderful plant. If it closed its leaflets upward, after the manner of a butterfly about to settle, fair weather was shown; when the leaflets remained flat, changeable and gloomy weather was indicated; while thunder at various distances was to be foretold by the curling of the leaflets, and the nearer the thunder the greater the curl, until when the points of the leaflets crossed, the thunderstorm was indicated as being overhead. Changes of wind, hurricanes, and other phenomena were to be shown by the various curious and beautiful movements of the leaflets and stalks. These movements undoubtedly took place, but when the plant was submitted to the unprejudiced observation of Dr. F. W. Oliver and Mr. F. E. Weiss, at Kew Gardens, those gentleman failed to find any connection between these movements and the weather, and Dr. Oliver made a report on the matter, which hits the heart of the whole subject of plant movements, by ascribing them for the most part to the agency of light and moisture. Mr. Scott, of the Meteorological Office, gave the finishing stroke to the theory by proving that the movements had no connection with either cyclones or with earthquakes, so that the sensitive plant may be considered as out of the list of weather guides, in spite of having been made the subject of an English patent.

It is a most common observation in the country that a large crop of hips, haws, and holly-berries indicates a severe winter to follow, and it is generally pointed out that nature thus provides winter food for the birds. This, too, is a fallacy.

Another weather fallacy, for which artists are responsible, is that flashes of lightning take the form of long angular lines of a zigzag shape, and of which I show you an example, taken from a work on the subject. This, when compared with the next view, which is a photograph taken direct from nature, shows that the artist had very little understood the true form of the lightning flash, which consists of numbers of short curves joining each other, something like the course of a river depicted on a map, or in some degree like the outline of a clump of leafy trees seen against the sky. But, as far as I know, there were only two artists whose acute vision saw lightning in anything like its true form. One was Turner, who long before the time of photography, scratched his lightning flashes with a penknife, making short curved dashes across the picture; and the other was Nasmyth, the astronomer and engineer, who also saw the lightning in its true form, and duly noted the same, only to be confirmed years afterwards, when it became easy to photograph the lightning flash itself. While on the subject of lightning, I may mention that it is recorded that in one case at least a rheumatic man who had been confined to bed six weeks, received a shock from a stroke of lightning, jumped from his bed, and ran down stairs completely cured. This is related in the Gentleman's Magazine for June 1820.

It has been often stated that the noise of cannon will produce rain, and it is not unusual in the Austrian Tyrol to hear the church bells ringing to avert thunder. These are fallacies. The experiments in America made recently to test whether rain could be produced by exploding a large quantity of gunpowder in the air, resulted in nothing except noise and smoke, though the thing was well worth trying.

Empedocles of old is credited with the invention for chasing

No. 1346 , vOL. 52$]$ 
away the Etesian winds by placing bottles made of the skins of asses on the hills to receive them. Timæus relates this. After hearing this about Empedocles, one is not surprised to learn that he thought there were two suns, that the moon was shaped like a dish, and that the sea was the sweat of the earth burnt by the sun. All this will be found in Stanley's "Lives of the Philosophers."

Almost in our own time, too, a "pluvifuge," or machine for blowing away rain, was proposed in Paris. This, too, was a fallacy.

To give an account of all the various ceremonies in savage and civilised countries which have been resorted to for the purpose of changing the course of the weather, would be here impossible ; but such rites have a common origin and a common result. They begin in error, and end in failure. In India, the rain-god is imagined to pour down showers through a sieve; in Peru there was supposed to be a celestial princess, who held a vase of rain, and when her brother struck the pitcher, men heard the shocks in thunder. In Polynesia rain comes from the angry stars, stoning the sun; while in Burmah it is still the custom to haul down rain by pulling at a rope. New Caledonia has its regular rain-making class of priests, and in Moffatt's time the rain-makers of South Africa were held in even higher estimation than the kings; and on the other side of the world the Alaskan propitiates the spirit of the storm by leaving tobacco for him in a cave. In our own country, too, there have been weather witches of various grades, and one described in Drayton's "Moon Calf"-

$$
\begin{aligned}
& \text { "Could sell winds to any one that would } \\
& \text { Buy them for money, forcing them to hold } \\
& \text { What time she listed, tie them in a thread } \\
& \text { Which, ever as the seafarer undid } \\
& \text { They rose or scantled as his sails would drive }
\end{aligned}
$$

To the same port whereat he would arrive."

The Finlanders at one time drove a profitable trade by the sale of winds. After being paid, they knitted three magical knots, and told the buyer that when he untied the first he would have a good gale; when the second, a strong wind; and when the third, a severe tempest. " Sir Walter Scott also mentions that King Eric, also called "Windy Cap," could change the direction of the wind by merely turning his cap round upon his head and old Scotch women are mentioned who, for a consideration, would bring the wind from any desired quarter. ${ }^{2}$ The Mandan Indian rain-maker had a rattle by the noise of which he called down rain from heaven by the simple process of keeping on long enough. It is safe to say that these are all fallacies.

From the rain-makers we may now turn for a moment to the almanack makers, and any one who will look up an old almanach of the early part of the last century, will find the greater part of it filled with lucubrations on the influence of the stars and constellations; he will also find a column giving for every day the parts of the body which are particularly under the celestial influences on the given dates, and when one sees for the first time this column reading-head, chest, legs, knees, feet, \&c., one wonders what it can mean; but it was then so well understood, as not even to require explanation, and there was generally too a rude woodcut of a hideous human figure, tattooed with the various signs of the zodiac to show the same thing. The sort of knowledge that passed for meteorology in I703 may be learned from the following extract from "Meteorologire" by Mr. Cock, Philomathemat. I703-a rare book in the possession of Mr. Symons.

"The twelve signs are divided into four sorts, for some be earthy, others watery, a third sort aery, and the fourth sort is fiery." The author then goes on to state that "Jupiter in the Skinker (whatever that may be) opposed by Saturn in the Lion did raise mighty South-west winds. ... Observe when a planet is in an earthy sign he was lately dried up by perambulating a fiery sign, and after that, immediately having made his progress in an earthy sign, is quite bound up from moisture."

It seems incredible that our ancestors, only a few generations back, could have.bought, paid for, and believed, such stuff as this. The early almanacks boldly gave a prediction for the weather for every ciay in the year ; but after a time confined themselves to a general statement of the weather, for instance "Part ridge's Almanack " for 1835 has the following prophecy for June : "Fertilising showers attended with thunder and lightning" this does for the first ten days. "Fair and at times hot" for the middle of the month, and "refreshing rain for the grass and corn" for any time between the 2 ist and the end of the month.

$$
\begin{aligned}
& 1 \text { Olaus Magnus, "His. of the Goths," } 1638 . \\
& 2 \text { Notes to "The Pirate." }
\end{aligned}
$$

No. I 346 , VOL. 527
Authors of weather almanacks had already begun to seek safety in vagueness. Some of these almanacks rose to a great popularity on the strength of one lucky guess ; and I think it is told of this same Partridge's almanack, or some other of the class, that it owed its reputation to a curious prophecy of extraordinary weather for July $3 \mathbf{I}$, when hail, rain, snow, thunder, \&c., were freely indicated. Forgetting that the month had 31 days the aimanack maker had omitted to insert the weather prediction for the last day, and a boy was sent from the printing office to know how the space was to be filled up. The weather prophet was too busy to attend to him, but at last in a passion, said : "Put down hail, rain, snow, thunder, anything"; and the boy taking it literally told the compositor, who duly set into type the extraordinary prediction, and which by a freak of nature came true, and made the fame and fortune of the almanack maker. This story, if not true, is at least ben trovato, and shows the force of the bard's statement-

$$
\begin{aligned}
& \text { "Our indiscretion sometimes serves us well } \\
& \text { When our deep plots do pall." }
\end{aligned}
$$

The British Almanack for 183I, published by the Useful Knowledge Society, had no weather predictions.

Patrick Murphy published a popular weather almanack, and his fame is said to have commenced by a lucky hit in one of the earlier issues by which he indicated which would be the coldest day of the year. There is a copy of this almanack for 1838 in the library of the Society, and some former owner has evidently taken the trouble to pencil in the actual weather opposite to that predicted. There were, according to this annotation, 89 incorrect forecasts, 9I doubtful, and the rest correct.

This Patrick Murphy was not a mere charlatan. He had a system, and though he differed from Sir Isaac Newton and the Royal Astronomical Society, he gave much study and research to the subject of meteorology - as shown by his various books. There was an Astro-Meteorological Society as late as I86I, and we have some mumbers of its Record's in our library.

Next comes the subject of weather prophets as distinguished from mere almanack makers; and who profess, sometimes for pelf, at other times for honour and glory, to predict the weather for any future date. These are always arising, and they do not lack a certain number of followers, who, possessing a large angle of credence, duly trumpet forth the successes of their chiefs, when they are so fortunate as to make any. The stock-in-trade of a prophet is of a slender and cheap description. He must have an inventive mind, a store of self-confidence, an insensibility to ridicule, and, above all, a keen memory for his successes, and a prompt forgetfulness of his failures. He should by choice have a theory, and this should be of the elastic order, so that if a predicted event does not punctually occur, he will be ready with a sort of codicil to amend it. Hence we find that the firing of guns has been cited as a sufficient reason for falsifying a weather prediction; and railways, too, are said to have an adverse influence, one author (not a prophet) telling us that they may be considered as "large winnowing machines, perpetually fanning and agitating the air with prodigious power, ploughing the air, as it were, and causing waves of vast extent, which, invisibly enlarging like the waves of the ocean, probably meet each other, clash, and produce modified effects, as resultants from adverse motions."

One of the first weather prophets mentioned in that delightful old book, Stanley's "Lives of the Philosophers," was Democritus, the Milesian; known as the "laughing philosopher," who foresaw a dearth of olives, and by buying up all he could get might have made a fortune, but gave it back to the bargainers with the remark, "You can see now that a philosopher can get rich when he pleases." Then there was Pherecydes, of whom Pythagoras was a favourite pupil, who prerlicted an earthquake three days in advance by the taste of the water from a certain well. Perhaps the earliest of all was Elijah, who trom the top of Carmel pointed out the coming squall cloud, and predicted a great rain. He forms a good model for imitation to the modern weather prophets, for he did not prophesy until he saw the storm coming, and he made no secret of his method. We have still amongst us in our country, mostly without honour, seers who supply us with weather predictions in various forms, from the modest duodecimo almanack to the flaring broadsheet which compels attention; but it would be a task too long to enter on a systematic refutation of their contradictory guesses at the weather. The last of these broadsheets that caught my eye had for the days of the gale of December I894, which Mr. C. Harding has described to us, the tame announcement of 
"generally overcast." This did not err on the side of boldness when considered with reference to one of the severest gales of the century.

A Spanish peasant whom I heard of in Andalucia, and who had the reputation of a weather prophet, wisely said, if you want to know the weather for to-morrow, ask me early in the morning. The Indian weather prophets who made a failure had to be silent altogether for the rest of their lives; and this causes us to regret that some of our own seers were not born in that distant land.

As to the so-called weather forecasts, they only come under the title of this paper when they fail, and as eight out of ten are said to be correct, I shall only say that they are honest attempts on the part of civilised governments to warn their people as far as possible against the march of known disturbances. I could wish that the term "weather indications" or "indicated weather" had been adopted, so as to make this plain to all, and that oftener, when the signs were vague, we had the simple announcement of no change indicated.

The director of this system so well known to us, and who is playfully called the "Clerk of the Weather," sometimes receives valuable hints, even from children; and I must quote one such communication.

"Please, Mr. Clerk of the Weather, tell the rain, snow, and hail to stop for the afternoon, and rain in the night."

I may conclude this section by saying that it is a great fallacy to suppose that there is such a thing as a weather prophet. All the great authorities agree that in the present state of our knowledge no human being can correctly predict the weather, even for a week to come.

And now we must consider a class of weather fallacies of which the victims can only excite in a well-regulated mind feelings of sadness and compassion, rather than the ridicule to which at first sight they seem more naturally entitled. I mean those weather prophets in whom the delicate mechanism of the mind is touched by disorder or decay, even if it has not already fallen under the stroke of complete dementia, and who believe that they can not only foresee the weather, but, by an effort of their own minds, control the elements and compel the clouds.

These patients I had hoped only existed in small numbers; but, on perusing the correspondence of a prominent meteorologist, kindly lent me for the purpose, I find that there are many of this class whose name, like that of the ancient wanderer among the tombs, is "Legion," and who still come on, each prepared to drive the chariot of the sun, or by an exertion of his own will, odylize (the word I suppose will come) all the powers of nature.

Dr. Johnson's Astronomer says in "Rasselas":- "Hear me, therefore, with attention. I have diligently considered the position of the earth and sun, and formed innumerable schemes, in which I changed their situations. I have sometimes turned aside the axis of the earth, and sometimes varied the ecliptic of the sun, but I have found it impossible to make a disposition by which the world may be advantaged. What one region gains another loses. Never rob other countries of rain to pour it on thine own."

This type of patient, as well as those who would use their supposed power for the purpose of creating fine weather during the holidays of the people, belong to the more noble sort, but there have been others, like the notorious Friar Bungay, who for sordid reasons have professed to exert a similar power. The only wonder is that anybody ever believed them.

Now, as this malady of the mind is not incurable, I will venture to offer a practical suggestion, and would recommend these patients who have nursed themselves into the belief that they possess the keys of the weather, to seek the hill-top on a summer afternoon-the air and exercise will do them good-and watch the fine fleeces of cumulus cloud as they sail majestically across the sky, each with its attendant shadow below. Let the patient concentrate his attention upon one single feathery cloud, and try by the exertion of his utmost force of will to make it pause for a moment in its career; and, if he fails--" as fail full well he may" -then let him banish from his mind for ever the idea that he can by his own will dominate the whole firmament. And if he has ever gone into print upon the subject, let him go home; and, like Prospero, his prototype, say-

$$
\begin{aligned}
& \text { "Deeper than ever plummet sounded, } \\
& \text { I"ll drown my book," }
\end{aligned}
$$

and so save the world from the trouble of investigating much pure nonsense. To these sufferers I can only repeat the words of one No. I 346 , voL. 52 ] of our own kings to the last man he touched for the evil-. "I wish you better health and more sense."

I must be forgiven for having only made a selection from the vast catalogue of fallacies which have accumulated about the subject, and I must continue to regret that there are still people who are ready to believe that the saints' days rule the weather, that the sun puts out the fire, that warm water freezes sooner than cold, or that a man is a prophet because he says so himself.

This Society is clearing the ground of many weeds, and already the fallacy of the "equinoctial" gales has been exploded (by Mr. Scott), while the churchyard ghost of the supposed fatal "green Christmas" has been most effectually laid by a recent statistical paper by Mr. Dines.

Some one may ask, after all this clearing away of fallaciesWhat have we left? and I would venture to refer him to all the patient work which is being done in various countries, and by which a real Science of Meteorology is being slowly built up, while to the outdoor weather student I wonld offer this consoling reflection-There is still the sky.

\section{UNIVERSITY AND EDUCATIONAL} INTELLIGENCE.

Prof. A. H. Church AND Dr. Fream have been offered and have accepted Honorary l'rofessorships at the Royal Agricultural College, Cirencester. These gentlemen were both formerly professors at the College, and both took part in the recent jubilee celebrations,

Ir would be a great advantage to the numerous students of science and technology if the scientific works in all public libraries were arranged in a separate class, and catalogued separately. This has been done for the Central Free Public Lending Library of Nottingham, by Mr. J. P. Briscoe, the librarian, and Mr. T. Dent. All the scientific books in the library have been arranged according to the science to which they refer, and indexed according to subjects and authors. The list will thus be of great assistance to students.

New technical schools, presented to Winsford, in the salt district of Cheshire, by Mr. Joseph Verdin, at a cost of $£ 8000$, were opened by the Duke and Duchess of Westminster last week. The money is part of a fund of $£ 26,000$, originally intended to compensate property owners from subsidences brought about by brine-pumping. As he was unable to transfer the fund, the Charity Commissioners were applied to, and it was decided that $£ \mathrm{I} 2,000$ should be used in the erection and endowment of technical schools at Winsford and Northwich.

Preceding a historical account of the Owens College, Manchester, contributed by Mr. P. J. Hartog to the current Record of Technical and Secondary Education, the function of university colleges in technical education is discussed. Mr. Hartog points to a fundamental distinction established by the Royal Commission on Technical Instruction between (I) institutions for the instruction of manufacturers and higher managers, and (2) institutions for the instruction of foremen and workmen engaged in industrial pursuits. He rightly remarks, however, that the distinction is still vague in the mind of the public, and even in that of many educationalists. It has become more vague through the use of the words "polytechnic" and "technical school" to render the German polyteihnicum and technische hochschutle, to which they are not at all equivalent. The polyteihnicum and technische hochsihule educate managers and manufacturers ; our polytechnics and technical schools, with their day-schools for lads and their night-schools for adults occupied during the day, educate foremen and workmen. It is not necesssary to insist on the inestimable value of the latter class of school ; but it is of the first importance that the public should perceive the distinction referred to by Mr. Hartog, and that they should not think that they are following the example of a cointry like Switzerland, which eleven years ago was spending over $\oint_{14}, 000$ a year on the Zürich Polytechnic, when they vote a large sum to one of the many English polytechnics and technical schools, now springing up so rapidiy with the help of funds derived from the Customs and Lxcise duties, while but meagre support is given to the institutions for the training of managers and manufacturers. As Mr. Hartog remarks, the university colleges combine the faculties of a German or Swiss university with those of a polytechnicum, but the existence of the technical part of the instruction given is often ignored because it is called university teaching, and not technical instruction, and 